\title{
ALOKASI WAKTU ANAK DALAM KELUARGA BAGI SISWA-SISWI SANGGAR SENI BINA MUSIKA DI \\ BATUSANGKAR, KABUPATEN TANAH DATAR
}

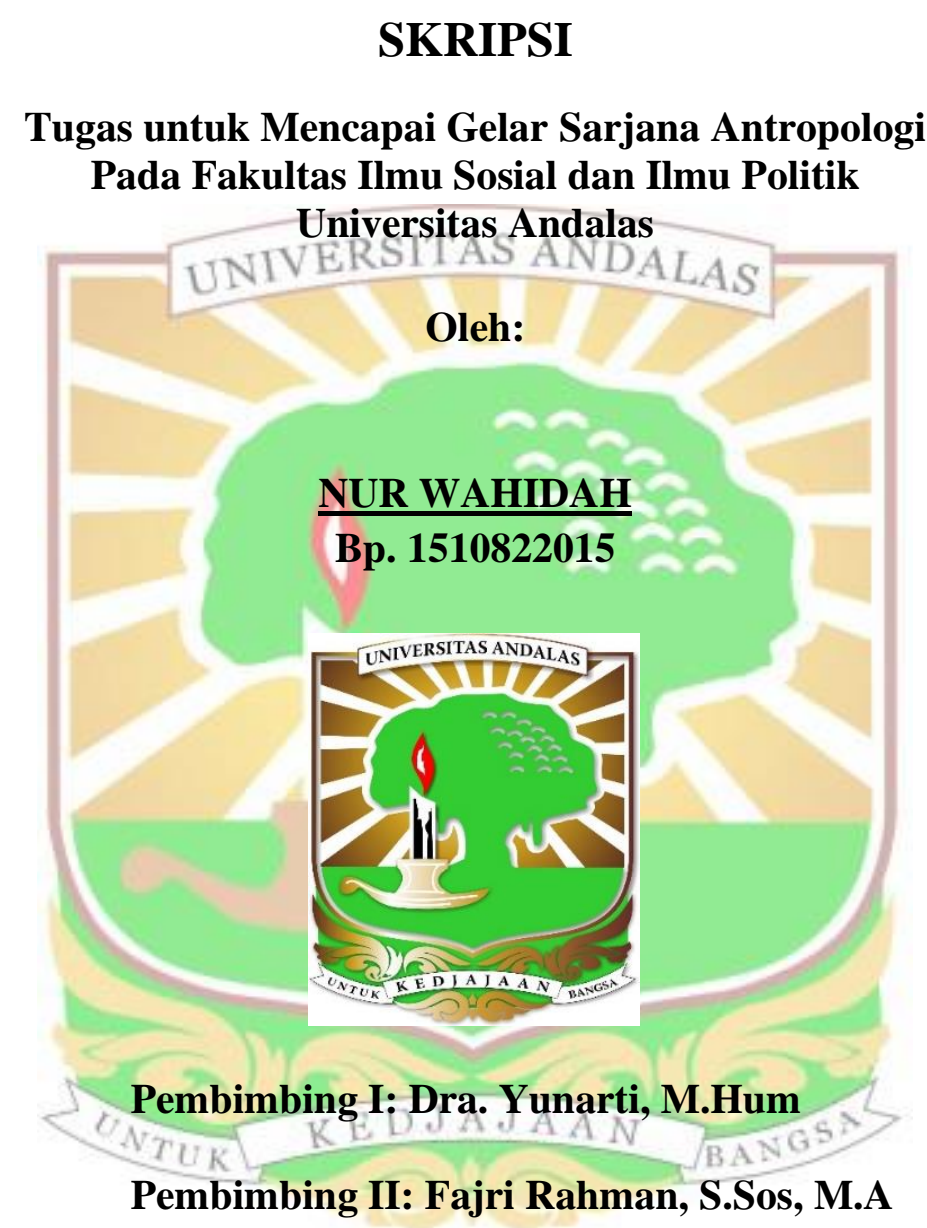

JURUSAN ANTROPOLOGI

FAKULTAS ILMU SOSIAL DAN ILMU POLITIK

UNIVERSITAS ANDALAS

PADANG 


\begin{abstract}
ABSTRAK
Nur Wahidah, BP: 1510822015. Jurusan Antropologi, Fakultas Ilmu Sosial dan Ilmu Politik, Universitas Andalas, 2019, Judul: "Alokasi Waktu Anak dalam Keluarga bagi Siswa-Siswi Sanggar Seni Bina Musika di Batusangkar, Kabupaten Tanah Datar)"

Pendidikan merupakan hal yang penting di dalam masyarakat. Transmisi nilai budaya terjadi melalui proses internalisasi, sosialisasi, dan enkulturasi dengan syarat adanya interaksi sosial dan waktu yang intens. Dalam perkembanga zaman, pendidikan ekstrakurikuler menjadi alternatif untuk pengembangan bakat. Hal ini tentunya berimplikasi kepada alokasi waktu anak dalam keluarga. Tujuan penelitian ini adalah untuk mengetahui latar belakang anak mengikuti kegiatan pengembangan bakat di sanggar seni Bina Musika, mendeskripsikan alokasi waktu anak seharihari, dan mendeskripsikan interaksi anak dalam keluarga.

Penelitian ini menggunakan pendekatan kualitatif yang bersifat deskriptif. Teknik pengumpulan data dalam penelitian ini yaitu observasi, wawancara, dokumentasi, dan studi kepustakaan. Pemilihan informan dilakukan dengan teknik purposive sampling, yaitu berdasarkan kriteria tertentu dengan tujuan agar dapat menjawab permasalahan penelitian. Informan penelitian ini terdiri dari siswa, orang tua siswa, pimpinan, dan pelatih sanggar seni Bina Musika.

Hasil penelitian ini menunjukkan anak-anak mengalokasikan waktu mereka sehari-hari untuk sekolah, ekstrakurikuler, belajar mengaji, les/privat, pekerjaan rumah, dan bermain. Proses belajar budaya tidak hanya terjadi di dalam keluarga. Peran penting orang tua telah dikuatkan oleh lembaga pendidikan lainnya baik secara formal maupun nonformal. Hal ini membuktikan bahwa proses belajar kebudayaan baik internalisasi, sosialisasi, dan enkulturasi juga berlangsung di luar lingkungan keluarga, termasuk di lingkungan sanggar seni. Banyaknya aktivitas yang dijalani di luar rumah membuat orang tua dan anak perlu mengalokasikan waktu dengan sebaik-baiknya untuk menjaga interaksi di dalam keluarga.
\end{abstract}

Kata kunci: Alokasi waktu, pendidikan nonformal, interaksi, keluarga 